\title{
Influence of eruptive style on volcanic gas emission chemistry and temperature
}

\author{
Clive Oppenheimer ${ }^{1 \star}$, Bruno Scaillet ${ }^{2}$, Andrew Woods ${ }^{3}$, A. Jeff Sutton ${ }^{4}$, Tamar Elias $\mathbb{D}^{4}$ and \\ Yves Moussallam ${ }^{1,5}$
}

\begin{abstract}
Gas bubbles form as magmas ascend in the crust and exsolve volatiles. These bubbles evolve chemically and physically as magma decompression and crystallization proceed. It is generally assumed that the gas remains in thermal equilibrium with the melt but the relationship between gas and melt redox state is debated. Here, using absorption spectroscopy, we report the composition of gases emitted from the lava lake of Kīlauea Volcano, Hawaii, and calculate equilibrium conditions for the gas emissions. Our observations span a transition between more and less vigorous-degassing regimes. They reveal a temperature range of up to $250^{\circ} \mathrm{C}$, and progressive oxidation of the gas, relative to solid rock buffers, with decreasing gas temperature. We suggest that these phenomena are the result of changing gas bubble size. We find that even for more viscous magmas, fast-rising bubbles can cool adiabatically, and lose the redox signature of their associated melts. This process can result in rapid changes in the abundances of redox-sensitive gas species. Gas composition is monitored at many volcanoes in support of hazard assessment but time averaging of observations can mask such variability arising from the dynamics of degassing. In addition, the observed redox decoupling between gas and melt calls for caution in using lava chemistry to infer the composition of associated volcanic gases.
\end{abstract}

T he redox state of magmatic gases is pertinent to understanding atmospheric evolution ${ }^{1}$ and ore formation ${ }^{2}$, and bears on interpretation of gas geochemical data for volcanic hazard evaluation ${ }^{3}$. Gas ratios such as $\mathrm{CO}_{2} / \mathrm{CO}, \mathrm{SO}_{2} / \mathrm{H}_{2} \mathrm{~S}$ and $\mathrm{H}_{2} \mathrm{O} / \mathrm{H}_{2}$ are redox sensitive and may show complex variations associated with changes in eruptive style ${ }^{4,5}$. Numerical models show that, during magma ascent, melt-gas equilibria can drive the magmatic redox state away from that of the reservoir or source region ${ }^{6,7}$. Such models assume, however, maintenance of thermal and chemical equilibrium between fluid and melt during decompression. While this assumption may hold for more viscous magmas, it may not be valid for basalts, by far the dominant product of global volcanism. For such low-viscosity melts, physical models predict that decoupling between gas and melt is likely during ascent ${ }^{8}$. Here we consider the case for the ongoing basaltic eruption at Kilauea Volcano, Hawaii.

\section{Composition of Kīlauea gas emissions}

The bulk of gas geochemical data for Kilauea stem from laboratory analyses of samples collected in the field, with necessary corrections made to account for air contamination, back-reaction during cooling, and interaction with sampling apparatus or host rocks ${ }^{9,10}$. More recent surveys have used open-path Fourier transform infrared spectroscopy (OP-FTS) to estimate relative proportions of C-, S- and halogen-bearing species ${ }^{11}$, and the pressure of gas segregation and its relationship to eruption style ${ }^{12}$. We extend this approach by measuring the redox-sensitive species carbonyl sulfide (OCS), which permits evaluation of gas redox state with high-temporal resolution ${ }^{13}$. Previous work at Kilauea, based on collection of gas samples, reached the conclusion that melt or rock buffers the gas redox state via oxygen exchange, even below the basalt solidus ${ }^{9}$. We revisit this hypothesis in the light of precise OP-FTS determinations of the molecular composition of gas emissions from the summit lava lake of Kilauea Volcano.
The spectrometer was positioned at the rim of Halema'uma'u Crater and viewing towards the lava surface, which acted as the infrared source, approximately $200 \mathrm{~m}$ distant (Fig. 1a; Methods). Gases emitted from the lava lake surface, following ascent through the magma, continually crossed the spectrometer's field of view. Our observations spanned two degassing regimes: initially, the lake surface motion was sedate (Fig. 1b) with sporadic isolated bubble bursts, but we later captured an episode of vigorous degassing associated with sustained lava spattering at points along the lake perimeter, driven by the ascent and rupture of bubbles of up to several metres in diameter (Fig. 1c and Supplementary Fig. 5). During this more energetic activity, we directed the spectrometer's field of view towards one of the spatter sources to maximize the contribution of its associated gas emission to the recorded absorption spectra. Over the long term, these degassing regimes are found to alternate, with spattering being the more prevalent ${ }^{14}$.

We analysed the abundances of $\mathrm{H}_{2} \mathrm{O}, \mathrm{CO}_{2}, \mathrm{CO}, \mathrm{OCS}, \mathrm{SO}_{2}, \mathrm{HF}$ and $\mathrm{HCl}$ in each spectrum acquired, correcting for water and $\mathrm{CO}_{2}$ contributions from ambient air to yield relative gas amounts for these seven species (Methods). Spectra were recorded approximately every $5 \mathrm{~s}$, and we regard each as a temporally discrete gas sample. The average composition, based on 995 spectra spanning the two degassing regimes, is as follows (all quantities in $\mathrm{mol} \%$ ): $\mathrm{H}_{2} \mathrm{O}$ 91.6; $\mathrm{CO}_{2}$ 4.37; $\mathrm{SO}_{2} 2.89 ; \mathrm{CO} 0.089 ; \mathrm{HCl} 0.047 ; \mathrm{HF} 0.030 ;$ OCS 0.00031 . The mean molar ratios of $\mathrm{SO}_{2} / \mathrm{HCl}$ and $\mathrm{H}_{2} \mathrm{O} / \mathrm{CO}_{2}$ are $\sim 68$ and $\sim 25$, respectively. This composition is more water rich and sulfur poor than some previous measurements of summit degassing from Kilauea ${ }^{15}$, though comparable to others ${ }^{16}$. Certain molecular ratios, such as $\mathrm{CO}_{2} / \mathrm{CO}$ vary significantly (Supplementary Fig. 1) for reasons explored below. The $\mathrm{CO}_{2} / \mathrm{H}_{2} \mathrm{O}$ ratios for the two degassing regimes overlap.

'Department of Geography, University of Cambridge, Cambridge, UK. Institut des Sciences de la Terre d'Orléans, CNRS/Université d'Orléans/BRGM, Orléans, France. ${ }^{3} \mathrm{BP}$ Institute, University of Cambridge, Cambridge, UK. ${ }^{4}$ Hawaiian Volcano Observatory, US Geological Survey, Hawai'i National Park, HI, USA. 'aboratoire Magmas et Volcans, Université Blaise Pascale - CNRS - IRD, OPGC, Clermont-Ferrand, France. *e-mail: co200@cam.ac.uk 


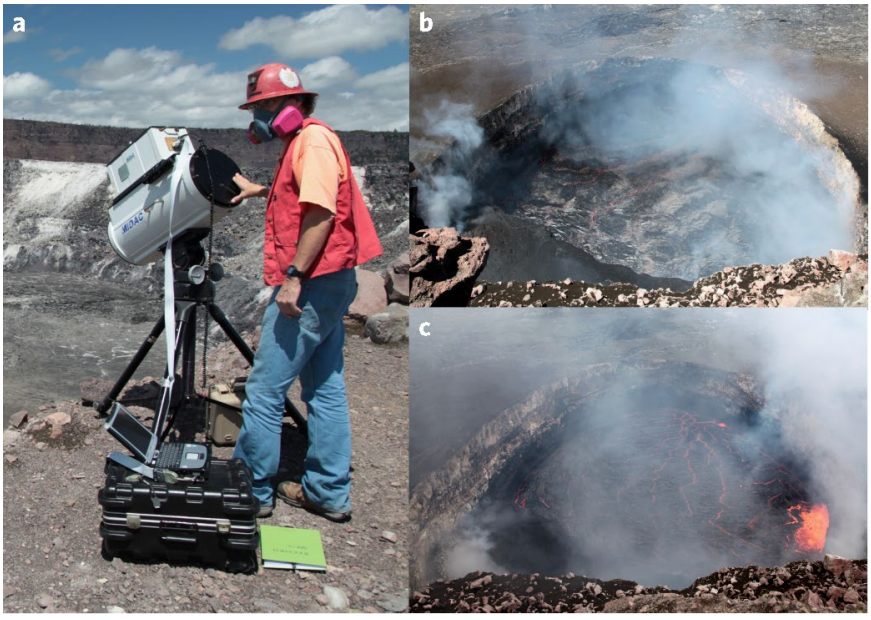

Fig. 1 | Instrument set up and lava lake behaviour at Halema'uma'u on 5 March 2013. a, Fourier transform infrared spectrometer with telescope pointed at the lava lake some $200 \mathrm{~m}$ distant. $\mathbf{b}$, Initial regime of mild degassing (non-spattering). c, Subsequent regime of vigorous degassing (spattering). The lava lake is approximately $200 \mathrm{~m}$ across.

\section{Low-pressure degassing}

The high water content suggests the magma has degassed its complement of volatiles up to atmospheric pressure ${ }^{12}$, consistent with interpretations of variability in lava lake level, gas chemistry and bulk outgassing ${ }^{17}$. To corroborate this, we re-examined analytical data for lavas dredged from the Puna ridge, which trends northeast of Kilauea, reaching about $6 \mathrm{~km}$ below sea level ${ }^{18,19}$. These lavas were quenched as they erupted on the seabed, and span a wide range of depths (and hence ambient water pressures). The volatile contents in their glassy rinds enable calculation of equilibrium gas compositions and eruption pressures using solubility laws for equivalent melts ${ }^{20-23}$ combined with gas equilibrium constants for the $\mathrm{C}-\mathrm{O}-\mathrm{H}-\mathrm{S}$ system ${ }^{24}$.

Although the recovered samples represent different eruptions, a conspicuous trend of increasing $\mathrm{H}_{2} \mathrm{O}$ with decreasing pressure emerges (Fig. 2a). Taken with the near 1:1 correlation between calculated and collection pressures (Fig. 2b), it demonstrates that this lava suite faithfully captures the first-order characteristics of degassing of shallow magmas beneath Kilauea. Extrapolation of the Puna trend towards atmospheric pressure indicates that the gases we measured with OP-FTS must have maintained gas-melt equilibrium over much of their ascent path into the lava lake that feeds the plume. Gas-melt separation at significant depths would be recorded by gas compositions richer in $\mathrm{CO}_{2}$ (that is, a water mole fraction of 0.6 at about 30 bar near the base of the lava lake, Fig. 2a), such as observed for some explosive events at Stromboli ${ }^{4}$. Sulfur and chlorine contents in the quenched glass of the Puna samples further substantiate this conclusion. The calculated trend, using a fluid-melt partition coefficient for $\mathrm{Cl}$ of 10 (refs ${ }^{25,26}$ ), shows consistently increasing molar $\mathrm{S} / \mathrm{Cl}$ ratio as pressure falls, reaching, at atmospheric pressure, $\sim 60$ (Fig. $2 \mathrm{c}$ ), consistent with the value of $\sim 68$ that we observe in the gas emission.

\section{Equilibrium temperature and redox calculations}

Having established that the gas emissions from the lava lake have equilibrated to atmospheric pressure, we can use our measurements of $\mathrm{CO}, \mathrm{CO}_{2}, \mathrm{SO}_{2}$ and OCS in the gas plume to determine, spectrum by spectrum, the oxygen fugacity $\left(\mathrm{fO}_{2}\right)$ and equilibrium temperature of the emitted gas (Fig. 3; Methods). Two striking features emerge from the data distribution. First, the computed equilibrium temperatures span a wide range, from about 900 to $1,150^{\circ} \mathrm{C}$,
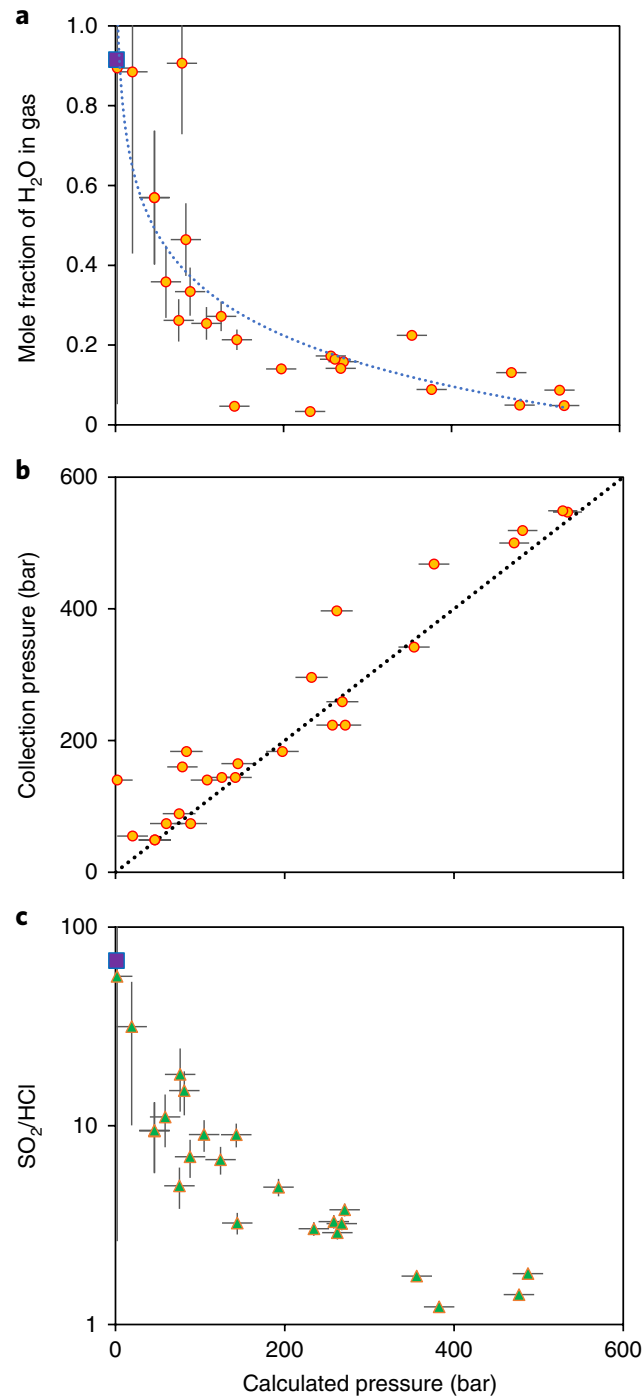

Fig. 2 | Observed and calculated gas properties for glass samples dredged from the Puna ridge. $\mathbf{a}$, Evolution of the mole fraction of water in the gas $\left(x \mathrm{H}_{2} \mathrm{O}\right)$ with pressure; dashed-line logarithmic fit is intended simply to guide the eye. $\mathbf{b}$, Comparison between modelled pressure of volatile saturation and the seabed pressure where each sample was collected (dashed line shows 1:1 correspondence). c, Evolution of the $\mathrm{SO}_{2} / \mathrm{HCl}$ molar ratio with pressure, calculated for $\mathrm{fO}_{2}=\mathrm{NNO}-0.5$. Our spectroscopic measurements of gas emissions from the lava lake are indicated by square symbols in $\mathbf{a}$ and $\mathbf{c}$. Gas compositions were computed by combining thermodynamic models of $\mathrm{H}_{2} \mathrm{O}$ and $\mathrm{CO}_{2}$ solubilities with measured volatile contents, assuming saturation at all levels, and incorporating a model for $\mathrm{fS}_{2}\left(\right.$ ref. $\left.{ }^{21}\right)$. These give the mole fractions of $\mathrm{C}-\mathrm{O}-\mathrm{H}-\mathrm{S}$ species (that is, $\mathrm{H}_{2} \mathrm{O}, \mathrm{SO}_{2}, \mathrm{CO}_{2}$ and so on). Temperatures for each sample were computed using a suitable geothermometer ${ }^{34}$. Error bars reflect \pm 10 ppm uncertainty in measured $\mathrm{CO}_{2}$ contents in glass, the largest source of uncertainty (particularly at low pressure).

extending below the solidus of Kilauea basalt $\left(980^{\circ} \mathrm{C}\right.$; ref. $\left.{ }^{27}\right)$. The higher computed temperatures are mostly associated with the milddegassing regime and the lower temperatures with the spattering episode but there is overlap between the two. Second, the temperature range corresponds to a change in the computed $\mathrm{fO}_{2}$ values from slightly above the quartz-fayalite-magnetite (QFM) redox buffer at $1,150^{\circ} \mathrm{C}$ to slightly above the NNO redox buffer at $900^{\circ} \mathrm{C}$. We consider first the implications of the temperature variation and then those of the relative $\mathrm{fO}_{2}$ shift. 


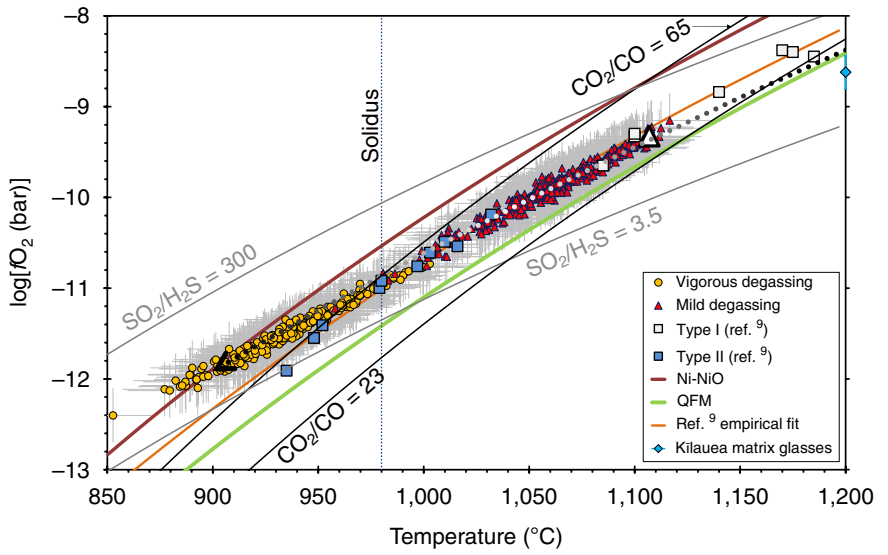

Fig. 3 | Computed equilibrium temperature and $\mathrm{fO}_{2}$ for spectrosccopic measurements of gas emissions from Kìlauea's lava lake. The dataset is classified into mild-degassing (12:14 to 13:14 h local time) and vigorousdegassing (15:16 to 15:23 h) regimes on 5 March 2013. Also shown are NNO and QFM buffers; the solidus temperature of Kilauea basalt; computed ranges for given values of $\mathrm{CO}_{2} / \mathrm{CO}$ and $\mathrm{SO}_{2} / \mathrm{H}_{2} \mathrm{~S}$; temperature$\mathrm{fO}_{2}$ calculations for 'type I' and 'type II' gases (Kïlauea Summit and East Rift Zone emissions, respectively) and associated empirical fit ${ }^{9}$; and reported $\mathrm{fO}_{2}$ at $1,200^{\circ} \mathrm{C}$ for 2008 and 2010 matrix glasses for ejecta from Halema'uma'u Crater (mean and range shown ${ }^{29}$. Note that, below the solidus, our analyses for 'vigorous degassing' are more oxidized than 'type II' gases at equivalent equilibrium temperatures. The white and black dotted line with arrow shows temperature- $\mathrm{fO}_{2}$ calculations for closedsystem, gas-only cooling starting with our measured gas composition at $1,150^{\circ} \mathrm{C}$ (open triangle), showing a close fit to the dataset.

\section{Effects of variable bubble size}

The wide range in calculated temperatures suggests gas cooling accompanying near adiabatic expansion of bubbles during ascent through the magma column. To test this hypothesis, we developed a simple thermodynamic model accounting for the radiative effects and expansion of bubbles due to decompression (Methods). This permits calculation of the degree of cooling of a rising bubble as a function of melt viscosity and final bubble size, which control speed of ascent (Fig. 4). The effect is strongest when the conductive heat flux from the melt is unable to keep pace with the work done as the bubble expands, that is, in the case of larger bubbles rising in lower viscosity melts. For a typical viscosity of Kilauea basalt of order $100 \mathrm{Pas}$, our model suggests that bubbles of radius $2-3 \mathrm{~m} \mathrm{cool}$ by an amount of order $100-200^{\circ} \mathrm{C}$. Due to the accelerating ascent of bubbles as they expand and the decrease in gas emissivity at low pressure, the cooling is most pronounced in the final tens of metres of passage below the surface, that is, within the lava lake.

This analysis leads us to view the computed equilibrium temperature for an individual spectrum (Fig. 3) as a proxy for bubble size population at an instant in time. As lake degassing becomes more vigorous, with larger bubbles reaching the surface and dominating the gas plume chemical signature that we record, gas temperatures drop due to increased cooling. Gas chemistry thus reflects the dynamics of degassing of the magma in the lake such that measurements made during even a brief period of variable activity yield a range of computed equilibrium temperatures. Each measurement captures the gas signature at an instant in time and cautions against temporal averaging of such compositional data.

The shift in equilibrium temperature accompanies a corresponding trend in $\mathrm{fO}_{2}$ and notably $\mathrm{fO}_{2}$ relative to established and empirical mineral buffers (Fig. 3). Between 1,000 and $1,100^{\circ} \mathrm{C}$, the correspondence between our measurements and previously reported estimates (squares in Fig. 3) is close, especially considering the distinct

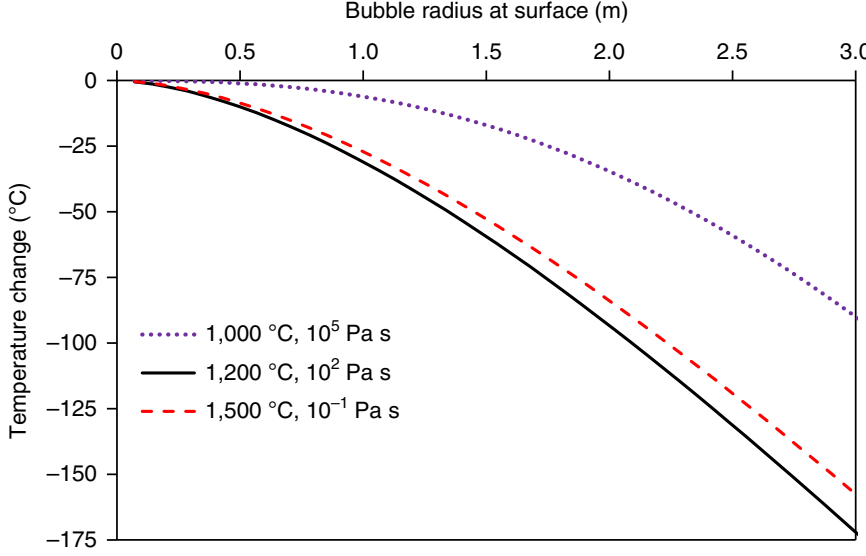

Fig. 4 | Amount of gas cooling as a function of final bubble radius (at the surface) and magma viscosity. Three temperature and viscosity scenarios are shown. The $1,200^{\circ} \mathrm{C}, 10^{2} \mathrm{~Pa}$ s case corresponds to Kilauea lava lake; the $1,000^{\circ} \mathrm{C}, 10^{5} \mathrm{Pas}$ case is applicable, for instance, to the phonolite lava lake of Erebus Volcano, Antarctica; while the $1,500^{\circ} \mathrm{C}, 10^{-1} \mathrm{Pas}$ case is intended to reflect early Earth magmas.

means by which the datasets were obtained (the 'type I' gas properties were calculated from analyses made at Halema'uma'u in 1917; ref. ${ }^{9}$ ). However, at temperatures below the solidus, our measurements increasingly trend towards the NNO buffer, in contrast to calculations for 'type II' gas samples collected at Kilauea's East Rift Zone in 1983 ( ref. $^{9}$ ). We interpret this decoupling as a further consequence of changes in bubble size, with larger bubbles increasingly unable to sustain gas-melt equilibrium as they rise (that is, gas in bubble interiors cannot effectively exchange oxygen with the melt). However, the internal equilibrium of the gas mixture can be expected to adjust rapidly to decompression and cooling-redox kinetics involving the species of interest at magmatic temperatures are fast (timescales of order $10^{-2} \mathrm{~s}$ ) with respect to bubble ascent rates in the conduit and lava lake ${ }^{28}$.

To test whether closed-system cooling can explain our observations, we compute the molecular speciation and $\mathrm{fO}_{2}$ for a gas-only mixture, as a function of temperature, starting with the observed elemental composition (C-O-S-H-Cl-F) at $1,150^{\circ} \mathrm{C}$. This mimics the trend of our spectroscopic observations closely (dashed line with arrow in Fig. 3) providing compelling evidence that the internal redox state of the gas is controlled by closed-system cooling during bubble expansion, with a dominant role played by sulfur owing to its abundance and range of oxidation states. The gas-only cooling trend is extrapolated in Fig. 3 to $1,200^{\circ} \mathrm{C}$, reaching the QFM redox buffer, and into the range of $\mathrm{fO}_{2}$ reported for matrix glasses of samples from Halema'uma'u Crater ejected in 2008 and 2010 (ref. ${ }^{29}$ )

The relationship of the $\mathrm{fO}_{2}$-temperature trend to the rock buffers for 'type I' and 'type II' Killauea gases (Fig. 3) has been explained by continuous exchange of oxygen between the gas and lava, even to sub-solidus temperatures ${ }^{11}$. The discrepancy with our observations may reflect differences in gas-lava interaction immediately after the escape of gases from the lava surface. In the case of our measurements, there was no obstruction to gas-air exchange above the exposed lava lake. In contrast, the 'type II' gases were sampled via tubing inserted into a confined space accessed through a narrow 'vigorously fuming' fissure $1-2 \mathrm{~m}$ above active lava'. The fissure was 'closed to the atmosphere at most points', and air contamination of the samples, determined analytically, was very low ${ }^{9}$. These circumstances may permit oxygen exchange between gas and lava even after gases escape, and as they expand and cool in the enclosure above the lava surface. 
In Fig. 4, we contrast the gas cooling for bubbles rising through a cooler, more viscous magma $\left(10^{5} \mathrm{~Pa} \mathrm{~s}, 1,000^{\circ} \mathrm{C}\right)$, and a hotter, less viscous magma $\left(10^{-1} \mathrm{Pas}, 1,500^{\circ} \mathrm{C}\right)$ than Kilauea's. For the high-viscosity case, the cooling is less pronounced owing to the lower rise speed of bubbles and the greater heating of the gas. The low-viscosity case is intended to simulate the higher temperatures $(1,400-$ $1,600^{\circ} \mathrm{C}$ ) and more mafic melt composition of the early Earth ${ }^{30,31}$. Here, the modelled cooling is somewhat less than the case for Kilauea. As the magma becomes less viscous $\left(10^{2}\right.$ to $\left.10^{-1} \mathrm{Pas}\right)$, the bubbles rise with inertial speed and so temperature plays a stronger role owing to the $T^{4}$ dependence. Hence, at $1,500^{\circ} \mathrm{C}$, the radiative heating of the bubble is stronger. Nevertheless, the cooling remains significant, and we speculate that decametre-sized bubbles rising rapidly through such hot and fluid melt would cool by hundreds of degrees, accompanied by significant redox shifts. If this is realistic, then the redox difference between magmas and their emitted gases should have been higher for the early Earth making the link between Earth's atmosphere and magmatism not as straightforward as commonly assumed ${ }^{32,33}$.

\section{Methods}

Methods, including statements of data availability and any associated accession codes and references, are available at https://doi. org/10.1038/s41561-018-0194-5.

Received: 11 October 2017; Accepted: 25 June 2018;

Published online: 6 August 2018

\section{References}

1. Gaillard, F., Scaillet, B. \& Arndt, N. T. Atmospheric oxygenation caused by a change in volcanic degassing pressure. Nature 478, 229-232 (2011).

2. Simon, A. C. \& Ripley, E. M. The role of magmatic sulfur in the formation of ore deposits. Rev. Mineral. Geochem. 73, 513-578 (2011).

3. Allard, P., Burton, M. \& Muré, F. Spectroscopic evidence for a lava fountain driven by previously accumulated magmatic gas. Nature 433, 407-410 (2005).

4. Burton, M., Allard, P., Muré, F. \& La Spina, A. Magmatic gas composition reveals the source depth of slug-driven Strombolian explosive activity. Science 317, 227-230 (2007).

5. Oppenheimer, C. et al. Mantle to surface degassing of alkalic magmas at Erebus volcano, Antarctica. Earth Planet. Sci. Lett. 306, 261-271 (2011).

6. Burgisser, A. \& Scaillet, B. Redox evolution of a degassing magma rising to the surface. Nature 445, 194-197 (2007).

7. Moretti, R. \& Papale, P. On the oxidation state and volatile behavior in multicomponent gas-melt equilibria. Chem. Geol. 213, 265-280 (2004).

8. Jaupart, C. \& Vergniolle, S. Laboratory models of Hawaiian and Strombolian eruptions. Nature 331, 58-60 (1988).

9. Gerlach, T. M. Oxygen buffering of Kilauea volcanic gases and the oxygen fugacity of Kilauea basalt. Geochim. Cosmochim. Acta 57, 795-814 (1993).

10. Greenland, L. P. Gas analyses from the Pu'u O'o eruption in 1985, Kilauea Volcano, Hawaii. Bull. Volcanol. 48, 341-348 (1986).

11. Edmonds, M. et al. Magma storage, transport and degassing during the 2008-10 summit eruption at Kilauea Volcano, Hawai' i. Geochim. Cosmochim. Acta 123, 284-301 (2013).

12. Edmonds, M. \& Gerlach, T. M. Vapor segregation and loss in basaltic melts. Geology 35, 751-754 (2007).

13. Peters, N., Oppenheimer, C., Killingsworth, D. R., Frechette, J. \& Kyle, P. Correlation of cycles in lava lake motion and degassing at Erebus Volcano, Antarctica. Geochem. Geophys. Geosyst. 15, 3244-3257 (2014).

14. Patrick, M. R., Orr, T., Swanson, D. A. \& Lev, E. Shallow and deep controls on lava lake surface motion at Kilauea Volcano. J. Volcanol. Geotherm. Res. 328, 247-261 (2016).

15. Gerlach, T. M. \& Graeber, E. J. Volatile budget of Kilauea Volcano. Nature 313, 273-277 (1985).

16. Naughton, J. J., Derby, J. V. \& Glover, R. B. Infrared measurements on volcanic gas and fume: Kilauea eruption, 1968. J. Geophys. Res. 74, 3273-3277 (1969).

17. Patrick, M. R., Anderson, K. R., Poland, M. P., Orr, T. R. \& Swanson, D. A. Lava lake level as a gauge of magma reservoir pressure and eruptive hazard. Geology 43, 831-834 (2015).
18. Dixon, J. E., Clague, D. A. \& Stolper, E. M. Degassing history of water, sulfur, and carbon in submarine lavas from Kilauea Volcano, Hawaii. J. Geol. 99 371-394 (1991).

19. Clague, D. A., Moore, J. G., Dixon, J. E. \& Friesen, W. B. Petrology of submarine lavas from Kilauea’s Puna Ridge, Hawaii. J. Petrol. 36, 299-349 (1995)

20. Dixon, J. E. \& Stolper, E. M. An experimental study of water and carbon dioxide solubilities in mid-ocean ridge basaltic liquids. Part II: applications to degassing. J. Petrol. 36, 1633-1646 (1995).

21. Scaillet, B. \& Pichavant, M. A model of sulphur solubility for hydrous mafic melts: application to the determination of magmatic fluid compositions of Italian volcanoes. Ann. Geophys. 48, 671-698 (2005).

22. Lesne, P., Scaillet, B., Pichavant, M., Iacono-Marziano, G. \& Beny, J. M. The $\mathrm{H}_{2} \mathrm{O}$ solubility of alkali basaltic melts: an experimental study. Contrib. Mineral. Petrol. 162, 133-151 (2011).

23. Lesne, P., Scaillet, B., Pichavant, M. \& Beny, J. M. The carbon dioxide solubility in alkali basalts: an experimental study. Contrib. Mineral. Petrol. 162, 153-168 (2011).

24. Holloway, J. R. Igneous fluids. Rev. Mineral. Geochem. 17, 211-233 (1987).

25. Alletti, M. et al. Chlorine partitioning between a basaltic melt and $\mathrm{H}_{2} \mathrm{O}-\mathrm{CO}_{2}$ fluids at Mount Etna. Chem. Geol. 263, 37-50 (2009).

26. Moretti, R. et al. Degassing vs. eruptive styles at Mt. Etna volcano (Sicily, Italy). Part I: volatile stocking, gas fluxing, and the shift from low-energy to highly explosive basaltic eruptions. Chem. Geol. 482, 1-17 (2018).

27. Wright, T. L., Peck, D. L. \& Shaw, H. R. in The Geophysics of the Pacific Ocean Basin and Its Margin (eds Sutton, G. H., Manghnani, M. H., Moberly, R \& Mcafee, E. U.) 375-390 (American Geophysical Union, Washington DC, 1976).

28. Burgisser, A. et al. Backward tracking of gas chemistry measurements at Erebus Volcano. Geochem. Geophys. Geosyst. 13, Q11010 (2012).

29. Moussallam, Y. et al. The impact of degassing on the oxidation state of basaltic magmas: a case study of Kilauea volcano. Earth Planet. Sci. Lett. 450 , 317-325 (2016)

30. Elkins-Tanton, L. T. Linked magma ocean solidification and atmospheric growth for Earth and Mars. Earth Planet. Sci. Lett. 271, 181-191 (2008)

31. Dingwell, D. B., Courtial, P., Giordano, D. \& Nichols, A. R. L. Viscosity of peridotite liquid. Earth Planet. Sci. Lett. 226, 127-138 (2004).

32. Li, Z. X. A. \& Lee, C.-T. A. The constancy of upper mantle $f_{2}$ through time inferred from V/Sc ratios in basalts. Earth Planet. Sci. Lett. 228, 483-493 (2004)

33. Holland, H. D. Volcanic gases, black smokers, and the Great Oxidation Event Geochim. Cosmochim. Acta 66, 3811-3826 (2002).

34. Wallace, P. \& Carmichael, I. S. Sulfur in basaltic magmas. Geochim. Cosmochim. Acta 56, 1863-1874 (1992).

\section{Acknowledgements}

This work was supported by the Natural Environment Research Council (through the Centre for the Observation and Modelling of Volcanoes, Earthquakes and Tectonics and grant NE/N009312/1) and LabEx VOLTAIRE (ANR-10-LABX-100-01). Y.M. received additional support from the Leverhulme Trust. We thank P. Kelly (US Geological Survey) for his review of the pre-submission manuscript. We are grateful to V. Tsanev for discussion on gas radiation at high temperature and pressure.

\section{Author contributions}

All authors contributed to preparation and revision of the manuscript. C.O. analysed and modelled spectroscopic data; B.S. modelled the melt-inclusion data; A.W. and C.O. developed the bubble-cooling model; A.J.S. and T.E. led the field campaign; and Y.M. contributed wider context on melt redox evolution.

\section{Competing interests}

The authors declare no competing interests.

\section{Additional information}

Supplementary information is available for this paper at https://doi.org/10.1038/ s41561-018-0194-5.

Reprints and permissions information is available at www.nature.com/reprints.

Correspondence and requests for materials should be addressed to C.O.

Publisher's note: Springer Nature remains neutral with regard to jurisdictional claims in published maps and institutional affiliations. 


\section{Methods}

Fourier transform infrared spectroscopy. We used a MIDAC Fourier transform infrared spectrometer with a Stirling-engine-cooled indium antimonide detector. Incoming light was collimated with a $25.4 \mathrm{~cm}$ Newtonian telescope (field of view $3 \mathrm{mrad}$ ). All spectra were recorded with a nominal optical path difference (retardation) of $2.0 \mathrm{~cm}$, corresponding to a $0.5 \mathrm{~cm}^{-1}$ spectral resolution Interferograms were Fourier transformed with a Mertz phase correction and triangular apodization. We then determined the column amounts of gases contributing to the recorded absorption spectra, employing a forward model ${ }^{35}$ that simulates the atmospheric transmittance in several discrete wavebands using line parameters for selected gas species taken from the HITRAN database (hitran. org). The model considers a one-layer atmosphere with pressure, temperature and initial column amounts specified for both atmospheric and volcanic gas species. Simulated spectra are adjusted to fit each observed spectrum using an optimal estimation method ${ }^{36}$.

There are several sources of uncertainty in the retrieved column amounts, notably the limitation of assuming a single-layer atmosphere (with uniform temperature), and the sensitivity of the instrument line shape to off-axis rays striking the interferometer. Much care, therefore, needs to be exercised in defining the limits of the spectral windows used for fitting. Our retrieval procedure includes calculation of a solution covariance matrix, whose diagonal elements represent the variance of each retrieved parameter, and which provides a measure of the retrieval error for each parameter fitted in each spectrum. The measurement error required to derive the covariance matrix is given by the standard deviation of the residual in the fit (that is, forward model minus observed spectrum). These calculated variances include contributions from the forward model error (arising from the selected instrument line shape used to represent the spectrometer's field of view and retardation), measurement noise, the information content of the measurement for each parameter fitted (dependent on the spectral microwindow for the fit) and the degrees of freedom (an inverse function of the number of parameters in the fit). Laboratory experiments using very similar equipment and retrieval methods have indicated that absolute accuracies of $\sim 5 \%$ or better can be achieved ${ }^{37}$.

Often, when absorption spectra such as ours are collected on a volcano over a span of an hour or so, scatter plots of retrieved column amounts for two gases are presented and used to compute average molecular ratios (for example, $\mathrm{CO}_{2} /$ $\mathrm{CO}, \mathrm{CO}_{2} / \mathrm{SO}_{2}, \mathrm{CO}_{2} / \mathrm{H}_{2} \mathrm{O}$ ). These regressions may hide real source variation, however ${ }^{38}$. If we treat each spectrum as an individual measurement, then we can examine rapid variations in gas composition. This requires careful correction for ambient air contributions to the measured water and $\mathrm{CO}_{2}$ abundances. Since other measured volcanic gas species, that is, $\mathrm{CO}, \mathrm{OCS}, \mathrm{SO}_{2}, \mathrm{HCl}$ and $\mathrm{HF}$, are present in negligible quantities in the ambient atmosphere, we can estimate background air contributions to $\mathrm{CO}_{2}$ and $\mathrm{H}_{2} \mathrm{O}$ from the intercepts of linear regressions of suitable scatter plots (for example, $\mathrm{CO}_{2}$ versus $\mathrm{SO}_{2}$; Supplementary Fig. 1). Note in this case that the molar $\mathrm{CO}_{2} / \mathrm{SO}_{2}$ ratio ranges from around 1.1 to 2.5 . A yet wider variation (a factor of six) is evident when looking at the redox pair $\mathrm{CO}_{2}$ versus $\mathrm{CO}$ (Supplementary Fig. 2).

Our gas 'samples' represent the molecules lying within the optical path between spectrometer and lake surface (the infrared source). Thus, an individual sample is likely to contain gas just released at the lava/air interface, as well as gas that has been circulating within the crater for a period. Given the continuous dispersion of the plume by convection and advection, most of gas molecules sensed under the conditions encountered were emitted within seconds or a few tens of seconds of the measurement. Thus, each spectrum approximates the near-instantaneous emission from the lava surface. Previous studies of the lava lake at Erebus Volcano, Antarctica, using similar equipment and methods have demonstrated the potential to track rapid variations in plume chemistry ${ }^{13}$.

Calculation of redox state and temperature. Volcanic gas compositions are often evaluated in terms of redox equilibria. This permits assessment of gas-rock or gas-melt exchange, and reactions between magmatic and hydrothermal fluids, or between gases and air. We consider two here, as they represent, sample by sample, the relationship between temperature, pressure and $\mathrm{fO}_{2}$ at equilibrium. We also have measurements for all the species concerned $\left(\mathrm{CO}, \mathrm{CO}_{2}, \mathrm{OCS}, \mathrm{SO}_{2}\right)$.

The first is:

$$
3 \mathrm{CO}+\mathrm{SO}_{2}=2 \mathrm{CO}_{2}+\mathrm{OCS}
$$

and the second:

$$
\mathrm{CO}+\frac{1}{2} \mathrm{O}_{2}=\mathrm{CO}_{2}
$$

Equation (1) is useful because the equilibrium is a function of pressure, $p$, as well as temperature, $T(\mathrm{~K})$ :

$$
\log _{10} p=\frac{-15,224}{T}+9.22608-\log _{10}\left\{\left(x_{\mathrm{CO}} / x_{\mathrm{CO}_{2}}\right)^{2}\left(x_{\mathrm{CO}} / x_{\mathrm{OCS}}\right) x_{\mathrm{SO}_{2}}\right\}
$$

where $x_{\mathrm{CO}}$ refers to the molar fraction of carbon monoxide, and so on, and in which the constants $(K)$, which are based on the reference state of the pure gaseous components at $1 \mathrm{bar}$, have been calculated using data tables in ref. ${ }^{39}$ and by regressing $\log K$ against $1 / T$ for the temperature range $727-1,227^{\circ} \mathrm{C}$. For each spectrum (sample), we readily obtain $x_{\mathrm{CO}} / x_{\mathrm{CO}_{2}}$ and $x_{\mathrm{CO}} / x_{\mathrm{OCS}}$ from the corrected retrieved column amounts of each gas. $x_{\mathrm{SO}_{2}}$ is obtained by normalizing all the seven species measurements $\left(\mathrm{CO}, \mathrm{CO}_{2}, \mathrm{OCS}, \mathrm{H}_{2} \mathrm{O}, \mathrm{SO}_{2}, \mathrm{HCl}\right.$ and $\mathrm{HF}$, after air correction). Adjustments can be made for estimated $\mathrm{H}_{2}$ and $\mathrm{H}_{2} \mathrm{~S}$ abundances but these only shift computed temperatures by $1-2^{\circ} \mathrm{C}$. The key assumption we then make is that the internal redox of the magmatic gas mixture equilibrates to atmospheric pressure, which is reasonable as gases will very rapidly reach equilibrium at temperatures above $800^{\circ} \mathrm{C}\left(\right.$ ref. $\left.{ }^{40}\right)$. This enables calculation of the equilibrium gas temperature, $T$ (in $\mathrm{K}$ ), for each sample. follows:

For equation (2), the equilibrium constant, $K_{2}$, is a function of $T$ and $f \mathrm{O}_{2}$, as

$$
\mathrm{CO}_{2} / \mathrm{CO}=K_{2} \sqrt{ } f \mathrm{O}_{2}
$$

This yields:

$$
\log _{10}\left(\frac{x_{\mathrm{CO}_{2}}}{x_{\mathrm{CO}}}\right)=\frac{14,724.5}{T}-4.5057+\frac{1}{2} \log _{10}\left(f \mathrm{O}_{2}\right)
$$

where $\mathrm{fO}_{2}$ is in bars and constants are again calculated from ref. ${ }^{39}$. Taking equilibrium $T$ computed as above (equation (3)), we can then determine $f \mathrm{O}_{2}$ for each sample.

For these calculations, the largest single source of uncertainty arises from the estimation of the background $\mathrm{CO}_{2}$ and $\mathrm{H}_{2} \mathrm{O}$ abundances (column amounts), as shown in Supplementary Fig. 1. The relative error in this correction is greatest for spectra with low volcanic gas contributions, so we excluded from further analysis those spectra for which the recorded $\mathrm{CO}_{2}$ column amount was less than $20 \%$ above background. We also looked closely at uncertainties in OCS determinations. Although the proportion of OCS that we calculate in the gas phase is only around $0.0003 \mathrm{~mol} \%$, the comparatively small abundance is compensated for by the strength of the molecule's absorption cross-section in the mid-infrared region of the spectrum, and the retrievals are robust. We excluded analyses for which the retrieved error on OCS exceeded $25 \%$. To test the sensitivity to uncertainties in these parameters, we varied them systematically to obtain error estimates of approximately $\pm 20^{\circ} \mathrm{C}$ in temperature and $\pm 0.3 \log$ units in $f \mathrm{O}_{2}$, as indicated in Fig. 3. We note that the precision on the measurements is much higher because most of the error sources are systematic, and we have analysed datasets collected over short intervals of time, which minimizes the effect of temporal variation in background atmospheric abundance of $\mathrm{H}_{2} \mathrm{O}$.

To justify further our assumption that equilibration proceeds to atmospheric pressure, we investigated the alternative scenarios. If we assume that $f \mathrm{O}_{2}$ follows the empirical buffer reported by ref. ${ }^{9}$, then we calculate again a wide range of equilibrium temperatures but pressures are found to be considerably less than atmospheric for most of the vigorous-degassing spectra. Further, computed pressure decreases with decreasing equilibrium temperature, which we cannot rationalize. Alternatively, if we fix the gas temperature to that of the magma, and compute $\mathrm{fO}_{2}$ and pressure, the latter values range between 30 and 400 bar. In this case, we cannot reconcile the manner of degassing observed at the surface with the implication that the emitted high-temperature gas preserves, all the way to the surface, such a high-pressure signature acquired at depth.

Model for bubble cooling. To estimate cooling of a bubble of mass $m$ rising through magma, we require a model of the rate of heat transfer, $H$, to the bubble from the melt, which buffers the cooling as the bubble expands. If the bubble volume changes by an amount $\Delta V$ in time $\Delta t$, the work done by the bubble is $p \Delta V$, where $p$ is the pressure, and this, along with the heat transfer, $H \Delta t$, leads to a change in the internal energy of the bubble, $m c_{\mathrm{g}} \Delta T_{\mathrm{g}}$, according to the relation:

$$
m c_{\mathrm{g}} \Delta T_{\mathrm{g}}=-p \Delta V+H \Delta t
$$

where $m$ is the bubble mass, $c_{\mathrm{g}}$ is the specific heat capacity of the gas and $\Delta T_{\mathrm{g}}$ its change in temperature. The pressure in the conduit is approximated by the magmastatic pressure, which applies provided that the bubble concentration in the conduit remains small. For a bubble of fixed mass rising at speed $u$, we can express equation (6) in terms of the height of the bubble in the conduit, in differential form:

$$
m c_{\mathrm{g}} \mathrm{d} T_{\mathrm{g}} / \mathrm{d} z=-p \mathrm{~d} V / \mathrm{dz}+H / u
$$

where $z$ is the distance above a reference level. Experimental data suggest that, if the Reynolds number (Re, given by $\rho_{\mathrm{m}} u r / \mu_{\mathrm{m}}$ where $\rho_{\mathrm{m}}$ and $\mu_{\mathrm{m}}$ are the melt density and dynamic viscosity, respectively, and $r$ is the bubble radius), exceeds 100 , the speed follows the approximate inertial law ${ }^{41}$ :

$$
u=0.3 \sqrt{ }(2 g r)
$$

where $g$ is the acceleration due to gravity. Alternatively, for $\operatorname{Re} \lesssim 10$, the speed may be approximated by 


$$
u=2 g\left(\rho_{\mathrm{m}}-\rho_{\mathrm{g}}\right) r^{2} / 9 \mu_{\mathrm{m}}
$$

where $\rho_{\mathrm{g}}$ is the gas density. We assume a simple transition from one regime to the other, as the bubble rises and Re increases, when the two speeds (8) and (9) are equal.

The heat flux, $H$, from the melt to the bubble depends on the bubble rise speed, and is given in terms of the average thickness of the thermal boundary layer in the melt around the bubble. As melt is displaced by the bubble, the boundary layer thickens from the top to the base of the bubble. As the flow around the bubble has timescale $2 r / u$, the average boundary layer thickness is of order $\left.\sqrt{(} \kappa_{\mathrm{m}} r / u\right)$, where $\kappa_{\mathrm{m}}$ is the thermal diffusivity of the melt. Experiments and numerical calculations $s^{42}$ for spherical bubbles with low $\operatorname{Re}(<100)$, as is the case for the majority of calculations herein, suggest the constants of proportionality for the average heat flux from the melt, leading to the following approximate law:

$$
H=\left(8 / \pi^{1 / 2}\right) \rho_{\mathrm{m}} c_{\mathrm{m}} \pi r^{2} \kappa_{\mathrm{m}}\left(T_{\mathrm{m}}-T_{\mathrm{s}}\right) /\left(\kappa_{\mathrm{m}} r / u\right)^{\frac{1}{2}}
$$

where $c_{\mathrm{m}}$ is the specific heat capacity of the melt, $T_{\mathrm{m}}$ its temperature and $T_{\mathrm{s}}$ is the average surface temperature of the bubble. This heat flux balances that from the melt surface to the gas in the bubble. This involves both convective and radiative heat transfer from the bubble surface to the gas in the bubble. The convective heat transfer, $H_{\text {conv }}$ scales with the Rayleigh number of the bubble, with a shape factor associated with the convective flow in the bubble. As a simplified parameterization, we write the convective flux using the relation for high Rayleigh number convection: ${ }^{43}$

$$
H_{\text {conv }}=0.4 \pi r \rho_{\mathrm{g}} c_{\mathrm{g}} \kappa_{\mathrm{g}}\left[g\left(T_{\mathrm{s}}-T_{\mathrm{g}}\right) r^{3} / T_{0} \kappa_{\mathrm{g}} v_{\mathrm{g}}\right]^{1 / 3}\left(T_{\mathrm{s}}-T_{\mathrm{g}}\right)
$$

where $T_{0}$ is a reference temperature for the gas in the bubble, here assumed to equal $T_{\mathrm{m}}$, and $\kappa_{\mathrm{g}}$ and $\nu_{\mathrm{g}}$ are the thermal diffusivity and kinematic viscosity of the gas, respectively. The radiative heat transfer between the melt at the surface and the gas in the bubble, $H_{\text {rad }}$, is given by the Stefan-Boltzmann law:

$$
H_{\mathrm{rad}}=4 \pi r^{2} \sigma E\left(T_{\mathrm{g}}, r, p\right)\left(T_{\mathrm{s}}^{4}-T_{\mathrm{g}}^{4}\right)
$$

where $\sigma$ is the Boltzmann constant and $E\left(T_{\mathrm{g}}, r, p\right)$ is the emissivity of the gas in the bubble. The emissivity depends on the mean path length of the radiation passing through the bubble ( $4 r / 3$ for a spherical geometry), with certain wavelengths of the radiation being absorbed and re-emitted by the gas. It also depends on the pressure and temperature of the gas. We simplify the estimation of emissivity by assuming that the gas is pure water vapour, which is reasonable given the high measured water contents in the pressure range of relevance (Fig. 2a). Emissivities of water at elevated temperatures and pressures have been investigated in the context of industrial furnaces and we have built an empirical model for emissivity as a function of bubble radius, gas temperature and pressure using the look up tables in ref. ${ }^{44}$

By equating the heat flux from equation (10) with the sum of heat fluxes from equations (11) and (12), we can find the average surface temperature of the gas bubble, $T_{\mathrm{s}}$, in terms of the far-field magma temperature, $T_{\mathrm{m}}$, and the mean gas temperature within the bubble, $T_{\mathrm{g}}$. With this value for $T_{\mathrm{s}}$, we can calculate the heat flux using equation (10) and the gas temperature, $T_{\mathrm{g}}$, of the bubble as it ascends by integration of equation (7).

We have solved the model for the case of water vapour bubbles rising from a depth of $1,500 \mathrm{~m}$ (the depth of the magma chamber located beneath the lava lake) to the surface. We find that, as the pressure falls off towards atmospheric pressure and the bubble accelerates upwards in the uppermost conduit and lava lake, the heat flux from the magma is unable to keep pace with the work done in expanding the bubble. It is here that the cooling is most pronounced. On reaching the surface, the gas temperature may be tens or even a few hundred degrees cooler than the magma, depending on the size of the bubble and the viscosity of the magma, which control the rise speed (Fig. 4).

The temperature of the bubble surface and of the vapour in the bubble for a given temperature and magma viscosity are shown in Supplementary Fig. 3. It is seen, in this case, that the surface temperature lags the gas cooling by between 5 and $50^{\circ} \mathrm{C}$.

We stress that our treatment here is simplified. There is uncertainty in the exact coefficients in equations (11) and (12), owing to the complexity of actual bubble shapes. For simplicity, we have taken them to be spherical but in reality they would have different shape factors as they stretch and become more elliptical. Also, the details of the flow associated with the convective mixing inside the bubble (equation (11)) and the model of the absorption of radiation (equation (12)) provide representative but simplified expressions for the magnitude of the heat transfer. For example, we neglect temperature variations around the bubble surface. To illustrate the sensitivity of the calculations to the detailed parameterization, Supplementary Fig. 4 compares the computed gas cooling as a function of final bubble size for gas emissivities 0.5 and 1.5 times the values taken from the look up tables of ref. ${ }^{44}$. While this changes the predictions, the magnitude of the cooling remains of a similar order. These changes in the value of the emissivity can be interpreted as uncertainty in the shape factor of the gas bubble, which may evolve into a non-spherical shape, as well as some of the uncertainty in the emissivity (which is only partially constrained at elevated temperatures and pressures). We conclude that these simple cooling estimates corroborate our explanation for the span of equilibrium temperatures calculated for the gas emissions from Kilauea and evident in Fig. 3.

Some estimates of bubble sizes are quoted in the literature cited in the main text. Supplementary Fig. 5 offers an impression of the sizes attained by rupturing bubbles during spatter episodes at Kilauea.

Data availability. The datasets generated and analysed during the current study are available from the corresponding author upon reasonable request and with permission of US Geological Survey Hawaiian Volcano Observatory.

\section{References}

35. Oppenheimer, C. \& Kyle, P. R. Probing the magma plumbing of Erebus Volcano, Antarctica, by open-path FTIR spectroscopy of gas emissions. J. Volcanol. Geotherm. Res. 177, 743-754 (2008).

36. Rodgers, C. D. Characterization and error analysis of profiles retrieved from remote sounding measurements. J. Geophys. Res. 95, 5587-5595 (1990).

37. Horrocks, L. A. et al. Open-path Fourier transform infrared spectroscopy of $\mathrm{SO}_{2}$ : an empirical error budget analysis, with implications for volcano monitoring. J. Geophys. Res. 106, 27647-27659 (2001).

38. Oppenheimer, C., Lomakina, A. S., Kyle, P. R., Kingsbury, N. G. \& Boichu, M. Pulsatory magma supply to a phonolite lava lake. Earth Planet. Sci. Lett. 284, 392-398 (2009).

39. Chase, M. W. NIST-JANAF Thermochemical Tables J. Phys. Chem. Ref. Data, Monograph No. 9 (ACS, AIP, NSRDS, 1998).

40. Martin, R. S., Mather, T. A. \& Pyle, D. M. High-temperature mixtures of magmatic and atmospheric gases. Geochem. Geophys. Geosyst. 7, Q04006 (2006).

41. Clift, R., Grace, J. R. \& Weber, M. E. Stability of bubbles in fluidized beds. Ind. Eng. Chem. Fundam. 13, 45-51 (1974).

42. Figueroa-Espinoza, B. \& Legendre, D. Mass or heat transfer from spheroidal gas bubbles rising through a stationary liquid. Chem. Eng. Sci. 65, 6296-6309 (2010).

43. Turner, J. S. Buoyancy Effects in Fluids (Cambridge Univ. Press, Cambridge, 1979).

44. Alberti, M., Weber, R. \& Mancini, M. Re-creating Hottel's emissivity charts for water vapor and extending them to 40 bar pressure using HITEMP-2010 data base. Combust. Flame 169, 141-153 (2016). 